\title{
MOLECULAR GEOCHEMICAL INDICATORS OF SEWAGE INPUT IN THE ANTARCTIC COASTAL AREA (ADMIRALTY BAY, KING GEORGE ISLAND, ANTARCTICA)
}

http://dx.doi.org/10.4322/apa.2014.010

César de Castro Martins*, Liziane Marcella Michelloti Ceschim, Edna Wisnieski \& Sabrina Nart Aguiar

Centro de Estudos do Mar, Universidade Federal do Paraná - UFPR, Pontal do Paraná, PR, Brazil *e-mail: ccmart@ufpr.br

Antarctica has been described as a pristine environment for many years. However, human presence has resulted in fossil fuel combustion, vehicular emissions, fuel spills in the marine and terrestrial environments and sewage waste discharged into the ocean. Currently, most Antarctic research stations (around 79 scientific centres) are located in coastal areas, and they release their untreated sewage containing domestic waste directly into the marine environment.

A group of molecular tracers such as steroids and linear alkylbenzenes (LABs) have been successfully used to investigate domestic waste discharges and faecal contamination in different regions, including Admiralty Bay, Antarctica (Martins et al., 2002; 2005). Coprostanol (5ß-cholestan$3 \beta$-ol) and coprostanone ( $5 \beta$-cholestan-3-one) have been widely used as faecal contamination markers because they are present in human faeces (Figure 1). Additionally, epicoprostanol ( $5 \beta$-cholestan- $3 \beta$-ol) indicates the level of treatment of the faecal matter as it is formed during the extensive anaerobic sewage treatment of wastewaters (Figure 1). Also, LABs are present at levels from 1 to $3 \%$ in surfactants and detergents with linear alkylbenzene sulphonates (LASs) due to incomplete sulfonation (Figure 2), and they are frequently discharged via sewage outfalls together with faecal matter. These compounds are usually preserved in the sediment, and can be used as molecular tracers of domestic wastes.

The monitoring of environmental conditions, such as hydrocarbon levels (Martins et al., 2004; 2010) and PCBs, near the sewage discharge from the Comandante Ferraz Brazilian Research Station, located at Martel Inlet, Admi- ralty Bay, King George Island, has been carried out since the austral summer of 1996/97.

The aim of this study is to evaluate the sewage contribution from Ferraz station to Admiralty Bay and to compare the historical trend reported in previous studies. This evaluation is based on the results of molecular geochemical indicators such as steroids and LABs from the upper layer of sediments sampled during the austral summers of 2009/10. In Antarctica, monitoring the extent of sewage pollution dispersal is essential as Antarctic Treaty signatory nations must conform to the Protocol on Environmental Protection.

Admiralty Bay is the largest around King George Island. The bay area is an Antarctic Specially Managed Area (ASMA), and the Scientific Committee on Antarctic Research (SCAR) has recommended environmental studies on present-day conditions of the region. Most sampling sites were located near Ferraz station. This medium size station was established in the summer of 1984, and usually has a population of approximately 50 people during the summer. The sewage system receives intermediate primary and secondary treatment before being discharged through a short pipe (Figure 3) near the sea. The sewage treatment system has been in operation since the austral summer of 1995/96 and was designed to serve a population of 50 .

For analyses of steroids, sediments are extracted using a Soxhlet system for 8 hours with $70 \mathrm{~mL}$ of ethanol. The concentrated extract is submitted to a clean up with column chromatography with deactivated alumina and elution with $15 \mathrm{~mL}$ of ethanol. The extract is evaporated till completely dry and derivatized to form trimethylsilyl ethers 


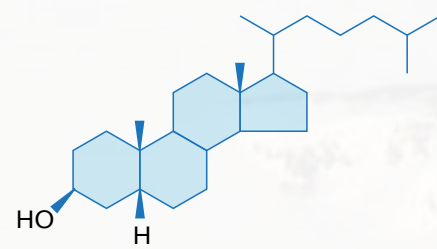

Coprostanol $(5 \beta(\mathrm{H})$-cholestan-3 $\beta$-ol)

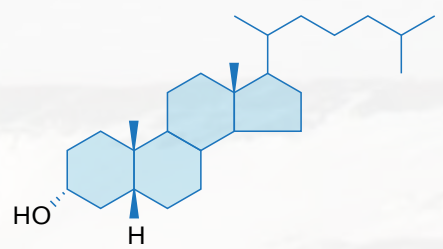

Epicoprostanol $(5 \beta(H)$-cholestan-3 $\alpha$-ol)

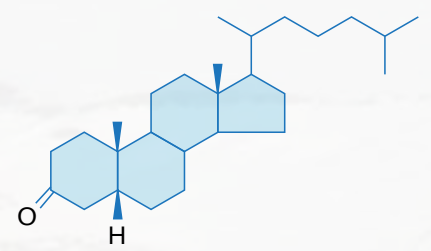

Coprostanone $(5 \beta(H)$-cholestan-3-one)

Figure 1. Chemical structures of fecal steroids used as indicators of sewage contribution.

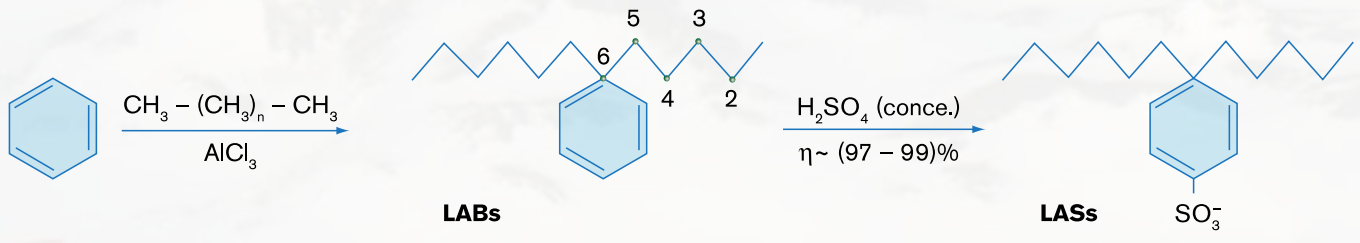

Figure 2. Chemical reactions involving LAB and LAS production.



Figure 3. Sample collection close to the sewage outfall under lowtide conditions (austral summer 2005).

using BSTFA (bis(trimethylsilyl)trifluoroacetamide) with $1 \%$ TMCS (trimethylchlorosilane) for 90 minutes at $65^{\circ} \mathrm{C}$. The steroid analyses are performed with an Agilent GC 7890A coupled to a flame ionization detector (FID).

For analyses of LABs, sediments are extracted using a Soxhlet system for 8 hours with hexanes/dichlo- romethane (1:1). The concentrated extract is fractionated by adsorption of liquid chromatography into aliphatic and aromatic hydrocarbons using a column of alumina and silica gel, and hexanes and 3:1 dichloromethane/hexanes for aliphatic and LABs (F1) and aromatic (F2) fractions as eluent, respectively. The fractions are concentrated and the volume adjusted to $1 \mathrm{~mL}$. The LABs analyses are performed with an Agilent GC 6890 coupled to an Agilent Mass Spectrometer Detector (model 5973N).

The results of this project and the comparison with previous studies to be developed at Admiralty Bay will provide an insight into the status of sewage contamination in Antarctica and could show that even human occupation for scientific purposes may be responsible for changes in a pristine environment. For this reason, monitoring programs are required to determine continuing trends and prevent the increase of anthropogenic impacts.

\section{References}

MARTINS, C. C.; VENKATESAN, M. I.; MONTONE, R. C. Sterols and linear alkylbenzenes in marine sediments from Admiralty Bay, King George Island, South Shetland Islands. Antarctic Science, v. 14, p. 244-52, 2002.

MARTINS, C. C. et al. Sterols and fecal microorganisms in sediments from Admiralty Bay, Antarctica. Brazilian Journal of Oceanography, v. 53, p. 1-12, 2005.

MARTINS, C. C. et al. Aliphatic and polycyclic aromatic hydrocarbons in surface sediments in Admiralty Bay, King George Island, Antarctica. Antarctic Science, v. 16, p. 117-22, 2004.

MARTINS, C. C. et al. Historical record of polycyclic aromatic hydrocarbons (PAHs) and spheroidal carbonaceous particles (SCPs) in marine sediment cores from Admiralty Bay, King George Island, Antarctica. Environment Pollution, v. 158, p. 192-200, 2010. 